\title{
Structural Model and De-Intercalation Kinetics of Kaolinite-Methanol-Sodium Stearate Intercalation Compound
}

\author{
Sen Wang, ${ }^{a, b}$ Xiaochao Zuo, ${ }^{a}$ Hongfei Cheng, ${ }^{*, a, b}$ Yongjie Yang ${ }^{a}$ and Qinfu Liu*,a \\ ${ }^{a}$ School of Geoscience \& Surveying Engineering and ${ }^{b}$ State Key Laboratory of Coal Resources \& \\ Safe Mining, China University of Mining \& Technology, 100083 Beijing, China
}

\begin{abstract}
Kaolinite-methanol-sodium stearate intercalation compound (Ka-MeOH-SS) was prepared by intercalation of kaolinite with dimethyl sulfoxide (DMSO) followed by displacing of DMSO with methanol and methanol by sodium stearate. The sample was characterized by X-ray diffraction (XRD), Fourier transform infrared spectroscopy (FTIR), thermal analysis (thermogravimetry (TGA) and differential scanning calorimetry (DSC)) and transmission electron microscopy (TEM). The results show that the basal spacing of $\mathrm{Ka}-\mathrm{MeOH}-\mathrm{SS}$ was enlarged to 45.5-47.9 $\AA$ and parts of its layers cocked and curled. Stearate ions were grafted on the methoxy groups and arrayed aslant in the interlayer space of kaolinite with an inclination angle of $47.45^{\circ}$ to $52.17^{\circ}$. Sodium ions were adsorbed around the $\mathrm{SiO}_{4}$ tetrahedron and interlayer carboxylate anions, whereas some of them entered into the ditrigonal hole of tetrahedral sheets. The thermal de-intercalation of $\mathrm{Ka}-\mathrm{MeOH}-\mathrm{SS}$ includes three steps and the activation energy $\mathrm{E}$ is $98.3 \mathrm{~kJ} \mathrm{~mol}^{-1}$, logarithm of pre-exponential factor $\lg \left(\mathrm{A} / \mathrm{s}^{-1}\right)$ is 9.71 and the mechanism function is $\mathrm{f}(\alpha)=-\ln (1-\alpha)$ and $\mathrm{G}(\alpha)=1-\alpha$.
\end{abstract}

Keywords: kaolinite, sodium stearate, intercalation, structural model, kinetic

\section{Introduction}

Functional nanocomposites assembled by organic/ inorganic building blocks at a molecular level have gained considerable interest in the field of solid material chemistry. ${ }^{1,2}$ Layered silicate has been widely used as the inorganic matrix for intercalation owing to its rich sources, unique structure and expandable layers. By decoration of organic guest molecules to the layers, materials with distinct characteristics and controllable physicochemical properties can be fabricated. ${ }^{3-5}$

Kaolinite $\mathrm{Al}_{2} \mathrm{Si}_{2} \mathrm{O}_{5}(\mathrm{OH})_{4}$ is a 1:1 type layered clay mineral with a crystal structure that consists of $\mathrm{SiO}_{4}$ tetrahedral sheets and $\mathrm{AlO}_{2}(\mathrm{OH})_{4}$ octahedral sheets in a periodic array along the c-axis. Fabrication of nano-kaolinite composites is an important approach to enlarge the application range of kaolinite and intercalation is the most effective method to prepare nano-kaolinite currently. ${ }^{6,7}$ Because the adjacent layers of kaolinite are linked by hydrogen bonds without exchangeable positive ions between layers, only a few varieties of micromolecules (e.g., dimethyl sulfoxide,,${ }^{8,9}$ urea, ${ }^{10}$ potassium acetate ${ }^{11-13}$ and hydrazine hydrate ${ }^{14}$ ) can enter into the interlayer directly, whereas

*e-mail: h.cheng@cumtb.edu.cn; lqf@cumtb.edu.cn the other non-polar micromolecules and macromolecules enter into the interlayer through "displacement". In 1999, Komori et al. ${ }^{15}$ prepared a kaolinite-alkylamine intercalation compound through secondary displacement and tentatively studied the property of this compound. Similarly, Matusik and Kłapyta ${ }^{16}$ prepared a kaolinitebenzyl ammonium chloride intercalation compound in 2013, enlarging the basal spacing of kaolinite to 1.4-3.8 nm and discussed the presence of benzyl ammonium chloride between the layers.

Sodium stearate is a salt of long-chain saturated fatty acid. Although acetate intercalated kaolinite has been widely studied, ${ }^{11-13}$ little work has been done on the study of kaolinite intercalation compound with sodium stearate. ${ }^{17}$ Moreover, previous study on sodium stearate intercalated kaolinite mainly focused on the preparation and characterization of the compound, ${ }^{17}$ and thus information on the structure of the model and the kinetics is limited.

In the present study, a kaolinite-methanol intercalation compound ( $\mathrm{Ka}-\mathrm{MeOH})$ was used as the precursor to prepare kaolinite-methanol-sodium stearate intercalation compound (Ka-MeOH-SS). The change in morphology of kaolinite and duration of intercalation, as well as its influence on the structure of the compound were studied. 
A structural model of Ka-MeOH-SS was proposed. In addition, the de-intercalation kinetics was investigated using thermodynamic method. "Kinetic Triplet" was obtained through determining the most probable mechanism function using Satava and Ozawa methods, and the activation energy $\mathrm{E}$ and pre-exponential factor A were calculated.

\section{Experimental}

\section{Materials}

A well-ordered kaolinite (denoted hereafter as Ka, 95 mass\%) with a Hinckley index of 1.31 from Zhangjiakou, Hebei Province, China, was used. The chemical composition of $\mathrm{Ka}$ (in terms of oxides) in mass \% is: $\mathrm{SiO}_{2}, 44.64 ; \mathrm{Al}_{2} \mathrm{O}_{3}, 38.05 ; \mathrm{Fe}_{2} \mathrm{O}_{3}, 0.22 ; \mathrm{MgO}, 0.06$; $\mathrm{CaO}, 0.11 ; \mathrm{Na}_{2} \mathrm{O}, 0.27 ; \mathrm{K}_{2} \mathrm{O}, 0.08 ; \mathrm{TiO}_{2}, 1.13 ; \mathrm{P}_{2} \mathrm{O}_{5}, 0.13$; $\mathrm{MnO}, 0.002$; and loss on ignition, 15.06. The dimethyl sulfoxide (DMSO), methanol and absolute ethyl alcohol were purchased from Xilong Chemical Company, China, whereas the sodium stearate were purchased from Beijing Chemical Reagents Company, China.

\section{Synthesis of intercalation compound}

$10 \mathrm{~g}$ of Ka was thoroughly mixed with $90 \mathrm{~mL}$ DMSO and $10 \mathrm{~mL}$ distilled water at $90^{\circ} \mathrm{C}$ for $6 \mathrm{~h}$. The solid product (Ka-D) in the mixture was separated by centrifugation and dried at $70{ }^{\circ} \mathrm{C}$ for 1 day. The method for intercalation of methanol was based on a previous report. ${ }^{18} 5 \mathrm{~g}$ of the Ka-D was added into $100 \mathrm{~mL}$ methanol at room temperature for 1 day. After the wet sample was separated by centrifugation, it was added to fresh methanol and stirred for 1 day again. This procedure was repeated 10 times, then a wet $\mathrm{Ka}-\mathrm{MeOH}$ was separated by centrifugation. $2 \mathrm{~g}$ of the wet $\mathrm{Ka}-\mathrm{MeOH}$ was mixed with $10 \mathrm{~g}$ of the sodium stearate and $100 \mathrm{~mL}$ ethanol solution ( 90 mass $\%$ ) at $80{ }^{\circ} \mathrm{C}$ for 3 days to prepare $\mathrm{Ka}-\mathrm{MeOH}-\mathrm{SS}$. The supernatant was discarded and the precipitate was washed for 3 times with ethanol (mass: volume $=1 \mathrm{~g}: 10 \mathrm{~mL}$ ) to remove excess sodium stearate. Finally, the solid product (Ka-MeOH-SS) was dried at room temperature for 2 days and ground into powder for further use.

\section{Characterization}

The X-ray diffraction (XRD) patterns were recorded on a Rigaku D/max 2500PC X-ray diffractometer with $\mathrm{Cu}$ $\mathrm{K} \alpha(\lambda=1.54178 \AA)$ irradiation in the $2 \theta$ range between 2.5 to $60^{\circ}$ at a speed of $2^{\circ} \mathrm{min}^{-1}$. Fourier transform infrared spectroscopy (FTIR) spectra were collected on a Thermofisher Nicolet 6700 spectrometer (32 scans at $4 \mathrm{~cm}^{-1}$ resolution) within the range of $400-4,000 \mathrm{~cm}^{-1}$ in $\mathrm{KBr}$ pellet form (2 mg sample in $200 \mathrm{mg}$ kilned $\mathrm{KBr}$ ). Thermogravimetric (TGA) and differential scanning calorimetric (DSC) analysis were performed with a Mettler-Toledo TGA-DSC I/1600 HT simultaneous thermal analyzer under a flowing nitrogen atmosphere $\left(100 \mathrm{~mL} \mathrm{~min}^{-1}\right)$. Approximately $20 \mathrm{mg}$ of sample power was placed in alumina crucibles and heated from 30 to $1,100{ }^{\circ} \mathrm{C}$ at a heating rate of $10{ }^{\circ} \mathrm{C} \mathrm{min}-1$. The kinetics of thermal de-intercalation of $\mathrm{Ka}-\mathrm{MeOH}-\mathrm{SS}$ in nitrogen was studied at several heating rates of $6,8,10$, and $12{ }^{\circ} \mathrm{C} \mathrm{min}^{-1}$ by thermogravimetric analysis (TGA). Transmission electron microscopy (TEM) observations were conducted on a $300 \mathrm{kV}$ FEI-Tecnai G2 F30 S-TWIN high-resolution transmission electron microscope.

\section{Results and Discussion}

\section{XRD analysis}

The XRD patterns of Ka, Ka-D, Ka-MeOH (wet) and $\mathrm{Ka}-\mathrm{MeOH}$ (dry) are shown in Figure 1. Ka exhibits a typical diffraction pattern with the $\mathrm{d}_{001}=7.2 \AA$ and $\mathrm{d}_{002}=3.6 \AA$ at $12.32^{\circ}$ and $24.85^{\circ}(2 \theta)$ (Figure 1a), respectively. The two values matched well with the standard ICDD reference pattern 14-0164 [kaolinite, $\mathrm{Al}_{2} \mathrm{Si}_{2} \mathrm{O}_{5}(\mathrm{OH})_{4}$ ]. It is the characteristic value for this mineral. When Ka was intercalated with DMSO, the $\mathrm{d}_{001}$ value was expanded from 7.2 to $11.3 \AA$ (Figure 1 b), confirming the intercalation of DMSO molecules into the interlayer space of Ka, which is in agreement with the results published before. ${ }^{19-21}$ The basal reflection of $\mathrm{Ka}-\mathrm{MeOH}$ (wet), the methanolintercalated Ka obtained in a wet state, is $9.2 \AA$ (Figure 1c). According to previous studies, ${ }^{18,22}$ the configuration of $\mathrm{Ka}-\mathrm{MeOH}$ (wet) is a typical interlayer structure which is composed of monolayer methanol molecules between the siloxane surface and the methoxy-modified inner surface in which the initial aluminol $(\mathrm{AlOH})$ groups in the interlayer space were converted to AlOMe groups. After the drying, the $\mathrm{d}_{001}$ value of $\mathrm{Ka}-\mathrm{MeOH}$ (dry) was reduced to $8.6 \AA$ (Figure 1d). This decrease in $\mathrm{d}_{001}$ value was caused by the escape of free methanol molecules from the interlayer space of Ka during drying process. ${ }^{17,18,22}$

The XRD patterns of $\mathrm{Ka}-\mathrm{MeOH}-\mathrm{SS}$ at different reaction time were shown in Figure 2. A new peak at a distance of $45.5 \AA$ close to $2^{\circ}(2 \theta)$ can be clearly identified in Figure 2a, which signifies the penetration of sodium stearate molecules into the interlayer space of Ka, resulting in an increment of interlayer distance by $38.3 \AA$. The $\mathrm{d}_{001}$ values of Ka-MeOH-SS at 24, 48 and $72 \mathrm{~h}$ are 


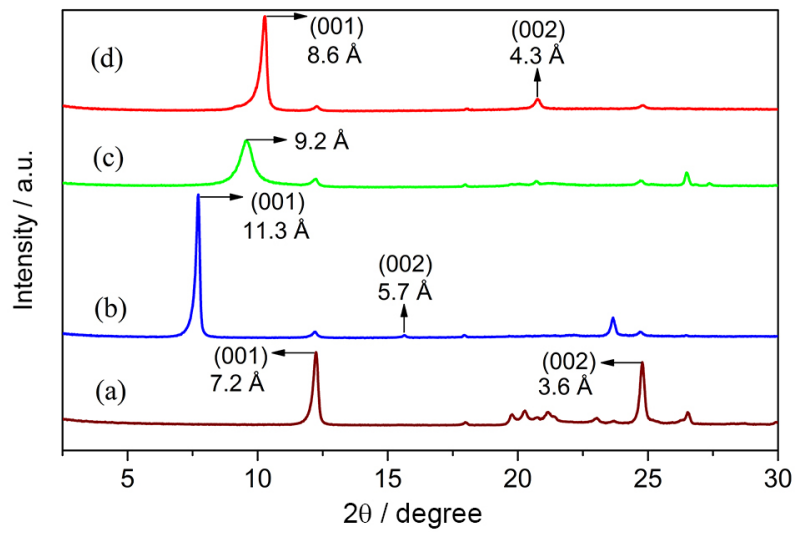

Figure 1. XRD patterns of Ka and Ka intercalation compounds: (a) Ka; (b) Ka-D; (c) Ka-MeOH (wet); (d) Ka-MeOH (dry).

45.5, 46.4 and $47.9 \AA$ A, respectively, which shows a slight tendency to grow with prolonged time. This phenomenon may be attributed to the change of the arrangement mode or inclination angle of sodium stearate molecules in the interlayer space of Ka. Moreover, two diffraction peaks belonging to the $\mathrm{d}_{001}$ planes of $\mathrm{Ka}$ and $\mathrm{Ka}-\mathrm{MeOH}$ (dry) are also observed at $12.35^{\circ}$ and $10.28^{\circ}(2 \theta)$, respectively, indicating that partially pure $\mathrm{Ka}$ and $\mathrm{MeOH}$-intercalated Ka remain after the grafting process. The intercalation ratio of $\mathrm{Ka}-\mathrm{MeOH}-\mathrm{SS}$ is $80.2 \%$, as calculated from the equation Intercalation ratio $=I_{I} /\left(I_{I}+I_{k}\right)$, where $I_{I}$ and $I_{K}$ are the intensities of (001) diffraction of the compound and unexpanded Ka component in the compound, respectively. ${ }^{23}$

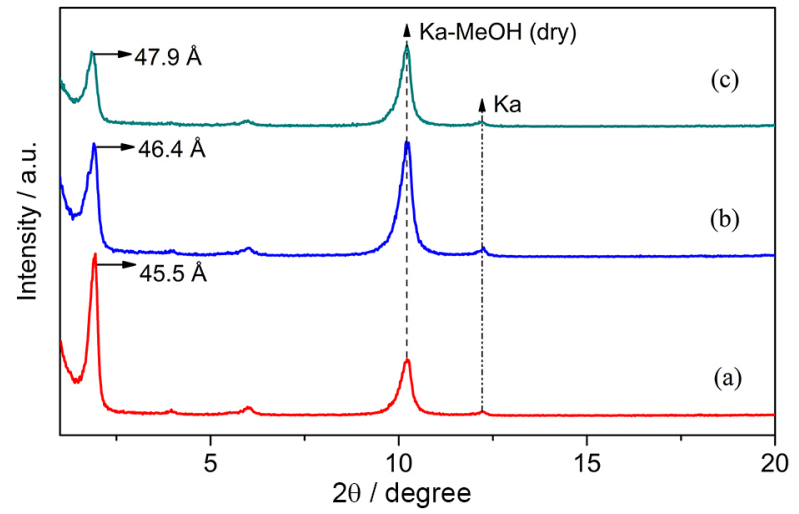

Figure 2. XRD patterns of Ka-methanol-sodium stearate intercalation compounds at different time: (a) $24 \mathrm{~h}$; (b) $48 \mathrm{~h}$; (c) $72 \mathrm{~h}$.

\section{FTIR spectra}

The FTIR spectra of $\mathrm{Ka}, \mathrm{Ka}-\mathrm{MeOH}$ (dry) and $\mathrm{Ka}-\mathrm{MeOH}-\mathrm{SS}$ are shown in Figure 3. As is known for Ka, the absorption bands at 3686 and $3655 \mathrm{~cm}^{-1}$ are ascribed to the stretches of inner-surface hydroxyls, whose intensities and positions are usually affected by intercalation and grafting of guest molecules, whereas the band at $3620 \mathrm{~cm}^{-1}$ belongs to the stretch of inner hydroxyls and it is generally not affected by guest molecules. ${ }^{6,24,25}$ Additionally, the vibrational bands at 938 and $913 \mathrm{~cm}^{-1}$ are associated with the bend of inner-surface $\mathrm{O}-\mathrm{H}$ and $\mathrm{Al}-\mathrm{OH}$ groups of Ka, respectively. ${ }^{26,27}$ The grafting of methanol molecules lead to a shift of Al-OH bending band at 913 to $906 \mathrm{~cm}^{-1}$ with a significant intensity loss (Figure 3b), indicating the formation of methoxy groups between methanol and inner-surface $\mathrm{Al}-\mathrm{OH}$ groups of $\mathrm{Ka}$ via an alcohol condensation reaction. ${ }^{22,28}$ However, the stretching vibration of inner hydroxyls at $3620 \mathrm{~cm}^{-1}$ has not been affected by this process, indicating that the graft of methanol are only on the inner-surface $\mathrm{O}-\mathrm{H}$. Moreover, an additional weak band at $1652 \mathrm{~cm}^{-1}$ is due to $\mathrm{O}-\mathrm{H}$ bending vibration of water molecules.

In the FTIR spectrum of Ka-MeOH-SS (Figure 3c), several typical vibrations bands of sodium stearate molecules, including 2920, 2852 and $1471 \mathrm{~cm}^{-1}$, are observed. The bands at 2920 and $2852 \mathrm{~cm}^{-1}$ correspond to the antisymmetric and symmetric stretching vibrations of $\mathrm{C}-\mathrm{H}$ groups, respectively, whereas the weaker band at $1471 \mathrm{~cm}^{-1}$ is caused by $\mathrm{C}-\mathrm{O}$ vibrations. ${ }^{18} \mathrm{In}$ the high-frequency region, alterations in both the intensity and position of vibrational band of inner-surface hydroxyls at $3693 \mathrm{~cm}^{-1}$ indicates the occurrence of hydrogen bonds between sodium stearate molecules and methoxy groups. In addition, comparing the FTIR spectra of $\mathrm{Ka}$ and $\mathrm{Ka}-\mathrm{MeOH}$ (dry), the characteristic band of inner hydroxyls at $3620 \mathrm{~cm}^{-1}$ shifted to $3625 \mathrm{~cm}^{-1}$. This may be attributed to the entrance of some sodium ions into the ditrigonal hole in the tetrahedral sheet of Ka during intercalation process, resulting in the change of vibrational mode of inner hydroxyls. Through the above data analysis, we suppose that sodium stearate molecules have been intercalated into the interlayers of Ka.

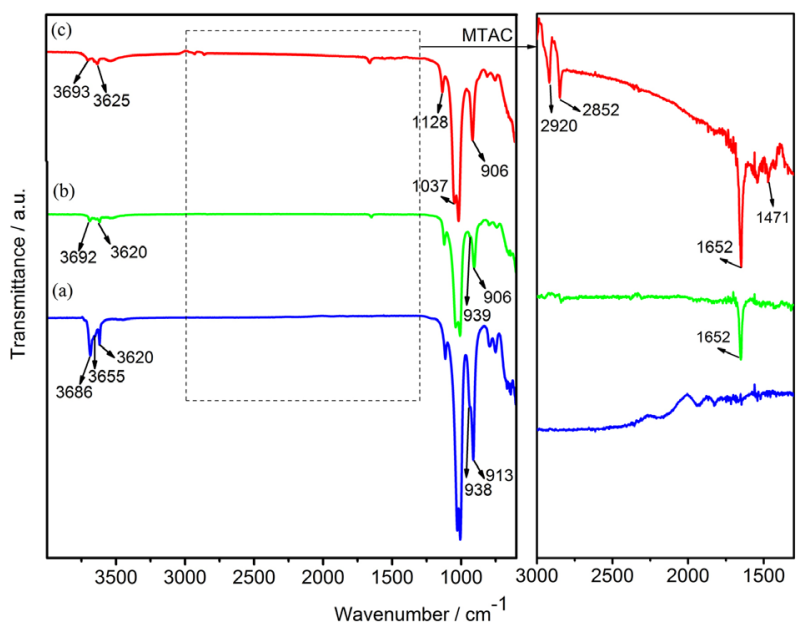

Figure 3. FTIR spectra of $\mathrm{Ka}$ and its intercalation compounds: (a) Ka; (b) $\mathrm{Ka}-\mathrm{MeOH}$ (dry); (c) Ka-MeOH-SS. 


\section{Transmission electron microscopy (TEM)}

The morphological characteristics of Ka, Ka-D, $\mathrm{Ka}-\mathrm{MeOH}$ and $\mathrm{Ka}-\mathrm{MeOH}-\mathrm{SS}$ were obtained from measurements of individual particles by TEM. Representative examples for each are displayed in Figure 4. Ka reveals a typical pseudo-hexagonal crystalline form containing straight edges and smooth surfaces (Figure 4a). Simplified as a circle particle, the average size of $\mathrm{Ka}$ is approximately $0.5-3 \mu \mathrm{m}$. The DMSO intercalation and methanol modification did not change the platy morphology of Ka (Figures $4 \mathrm{~b}$ and $4 \mathrm{c}$ ). It is observed that the shape of most Ka-MeOH-SS are platy particles, whereas parts of the layers cocked and curled (Figures $4 \mathrm{~d}$ and $4 \mathrm{f}$ ), resulting from the delamination and rolling of partial Ka particles. ${ }^{18}$ The intercalation of sodium stearate molecules into interlayers of Ka have obviously enlarged the interlayer space and further destroyed the hydrogen bonds between adjacent layers, which aggravated the mismatch of silicon-oxygen tetrahedron and aluminium-oxygen octahedron of $\mathrm{Ka}$,
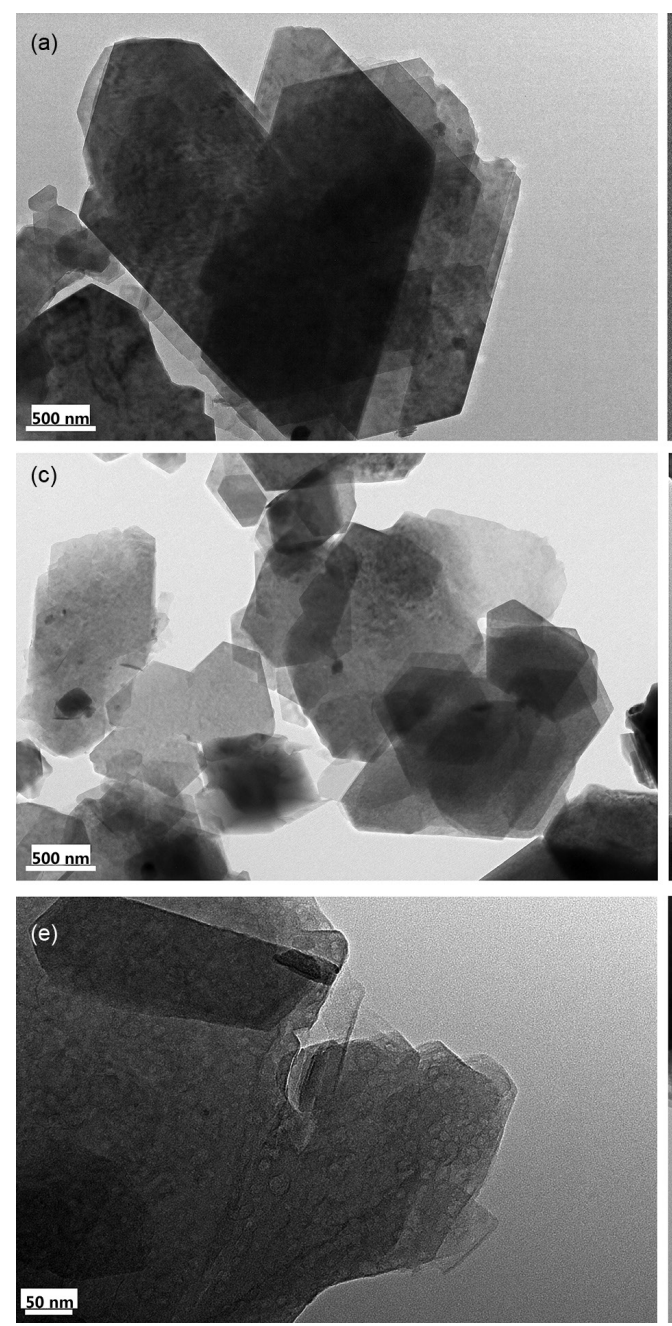

Figure 4. TEM imagines of Ka and its intercalation compounds: (a) Ka; (b) Ka-D; (c) Ka-MeOH; (d), (e) and (f) Ka-MeOH-SS. thus parts of the layers cocked and curled to achieve octet stability.

\section{Thermal analysis}

The TGA and DSC measurement of $\mathrm{Ka}$ and its intercalation compounds were performed and the results are shown in Figure 5. Only one mass loss was observed by $12.60 \%$ in the temperature interval of $450-650{ }^{\circ} \mathrm{C}$ on the TGA curve of the Ka, corresponding to the endothermic DSC peak at $529{ }^{\circ} \mathrm{C}$ (Figure 5a). The mass loss is considered to be caused by dehydroxylation process with formation of metakaolinite..$^{29-32}$ Moreover, one exothermic peak is also observed in the DSC curve at $996{ }^{\circ} \mathrm{C}$, without any mass loss in the TGA curve, which belongs to the crystallization of mullite. ${ }^{33}$

For Ka-MeOH (dry), two major mass losses of 2.03 and $12.54 \%$ occur in the ranges of $60-180$ and $383-607^{\circ} \mathrm{C}$ in the TGA curves, respectively (Figure $5 \mathrm{~b}$ ). The first is assigned to the elimination of physically adsorbed water or methanol
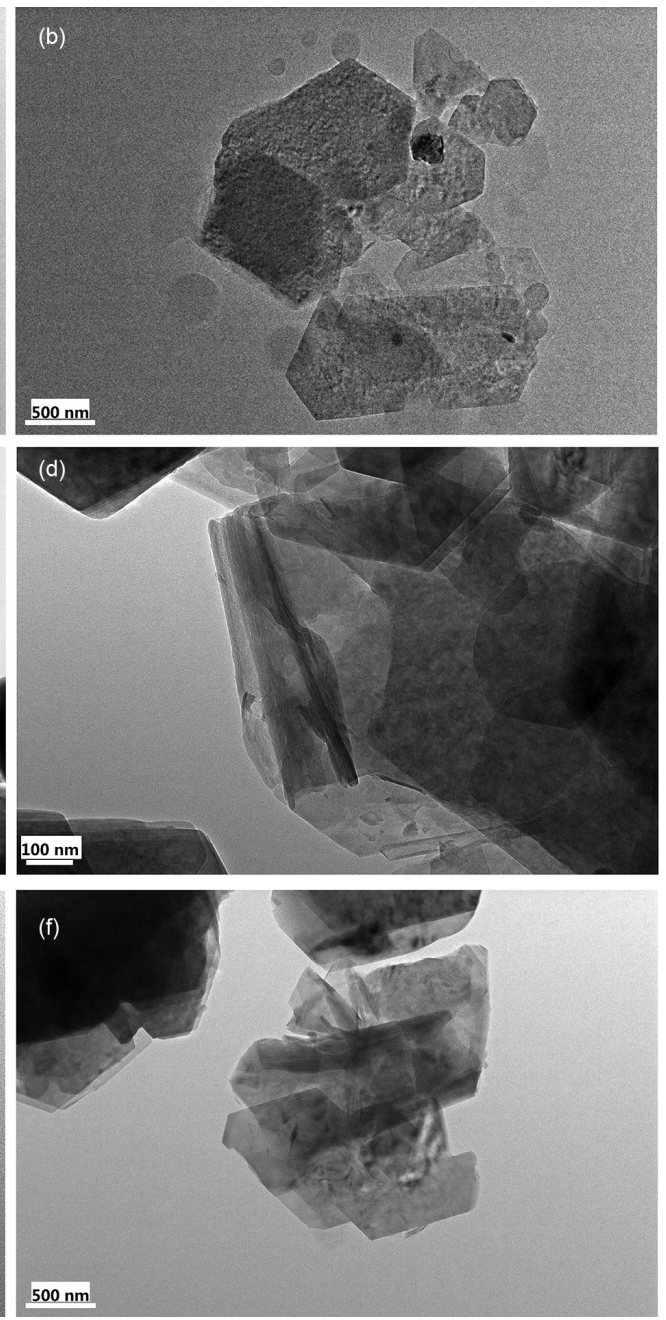
molecule, while the second is attributed to the removal of the grafted methoxy groups and the dehydroxylation of $\mathrm{Ka}^{18,29-31}$ The dehydroxilation also gives rise to an endothermic peak at $510{ }^{\circ} \mathrm{C}$ in the range of $383-607{ }^{\circ} \mathrm{C}$ in the DSC curve, which is apparently decreased comparing with that of original Ka. This may be due to the weakening of the interlayer hydrogen bonds and crystallinity of Ka during intercalation of methanol molecules. ${ }^{29,34,35}$

Three major mass loss steps were discovered on the TGA curve of Ka-MeOH-SS (Figure 5c): (i) a mass loss of $1.84 \%$ in the range of $70-180{ }^{\circ} \mathrm{C}$, corresponding to the removal of adsorbed water or methanol molecules, which is similar to the TGA curve of $\mathrm{Ka}-\mathrm{MeOH}$ (dry); (ii) a second mass loss of $2.95 \%$ in the range of $180-306^{\circ} \mathrm{C}$, accompanied by a DSC peak centered at $211^{\circ} \mathrm{C}$, which is due to the de-intercalation of intercalated stearate radical ions. This process was also corroborated by appearance of the new peak at 2920 and $2852 \mathrm{~cm}^{-1}$ in the FTIR spectra; (iii) a third mass loss between 405 to $650{ }^{\circ} \mathrm{C}$, corresponding to the DSC endothermic peak centered at $510^{\circ} \mathrm{C}$, which is attributed to the removal of the grafted methoxy groups and the dehydroxylation of Ka. Moreover, in the high temperature range $\left(800-1300{ }^{\circ} \mathrm{C}\right)$, a DSC exothermic peak at $999{ }^{\circ} \mathrm{C}$ is caused by the formation of $\gamma-\mathrm{Al}_{2} \mathrm{O}_{3}$ and the phase transformation from $\gamma-\mathrm{Al}_{2} \mathrm{O}_{3}$ and amorphous $\mathrm{SiO}_{2}$ to mullite, according to previous literatures. ${ }^{29,33,36}$

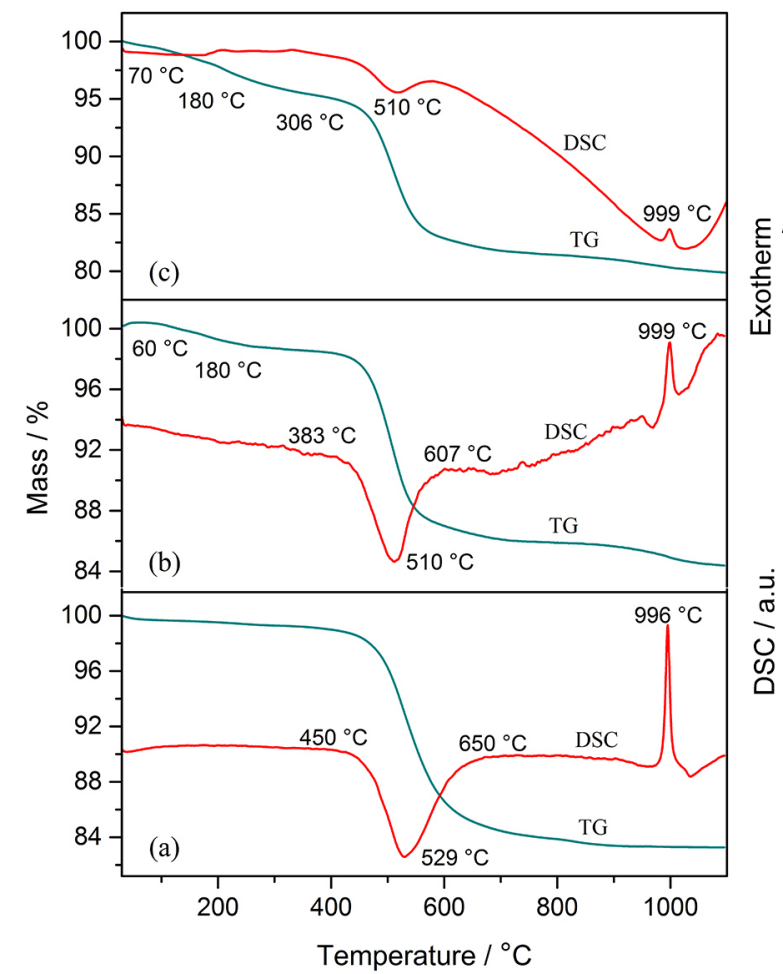

Figure 5. TGA and DSC curves of Ka and its intercalation compounds: (a) $\mathrm{Ka}$, (b) $\mathrm{Ka}-\mathrm{MeOH}$ (dry), (c) Ka-meOH-SS.

\section{De-intercalation reaction kinetics}

Kinetic study aims to obtain the "Kinetic Triplet" [pre-exponential factor A, activation energy $\mathrm{E}$ and kinetic model function $f(\alpha)$ or $G(\alpha)$ ] that can describe a chemical reaction. ${ }^{37}$ Thermal analysis and kinetic calculation of $\mathrm{Ka}-\mathrm{MeOH}-\mathrm{SS}$ can help characterize the de-intercalation process, speculate the intercalation mechanisms and provide scientific basis for control over intercalation reactions.

According to theories of isothermal kinetics, the kinetic equations of solid decomposition reaction are generally expressed as:

$$
\begin{aligned}
& \frac{\mathrm{d} \alpha}{\mathrm{dt}}=K(T) \cdot f(\alpha)=\operatorname{Aexp}\left(-\frac{E}{R T}\right) f(\alpha) \\
& G(\alpha)=K(T) d t=\int \operatorname{Aexp}\left(-\frac{E}{R T}\right) d t \\
& G(\alpha)=\int_{0}^{\alpha} \frac{d \alpha}{f(\alpha)}
\end{aligned}
$$

In the equations 1 to $3, \alpha, A, E, R, T, f(\alpha)$ and $G(\alpha)$ are percent conversion, pre-exponential factor $\left(\mathrm{s}^{-1}\right)$, apparent activation energy $\left(\mathrm{J} \mathrm{mol}^{-1}\right)$, universal gas constant $\left(\mathrm{J} \mathrm{mol}^{-1} \mathrm{~K}^{-1}\right)$, degree Kelvin $(\mathrm{K})$ and differential kinetic model and integral kinetic model functions, respectively. Moreover, in the process of raising temperature at an equal rate:

$\beta=\mathrm{dT} / \mathrm{dt}$

where $\beta$ is the heating rate $\left(\mathrm{K} \mathrm{min}^{-1}\right)$. Equations 1,2 and 4 are then combined, and Satava integral method is worked out through variables separation, integrated deformation, and derivation in other forms:

$\lg [\mathrm{G}(\alpha)]=\lg \left(\frac{\mathrm{AE}}{\beta \mathrm{R}}\right)-2.315-0.4567\left(\frac{\mathrm{E}}{\mathrm{RT}}\right)$

Equation 5 can be transformed into:

$$
\lg \beta=\lg \left[\frac{\mathrm{AE}}{\beta \mathrm{G}(\alpha)}\right]-2.315-0.4567\left(\frac{\mathrm{E}}{\mathrm{RT}}\right)
$$

For the peak temperature $\left(\mathrm{Tp}_{\mathrm{i}}\right)$ at various thermograms $\left(\beta_{\mathrm{i}}\right)$ :

$\lg \beta_{\mathrm{i}}=\lg \left[\frac{\mathrm{AE}}{\beta \mathrm{G}(\alpha)}\right]-2.315-0.4567\left(\frac{\mathrm{E}}{\mathrm{RTp}_{\mathrm{i}}}\right)$ 
The values of $\alpha$ are approximately equal for the different peak temperatures $\left(\mathrm{Tp}_{\mathrm{i}}\right)$, thus, the apparent activation energy $\mathrm{E}$ can be obtained through $\mathrm{Tp}$, which is the Ozawa method. A graph (Figure 6a) can be drawn according to the peak temperature at different heating rates and the activation energy $E$ in the reaction is $91.8 \mathrm{~kJ} \mathrm{~mol}^{-1}$.

Based on the Satava integral formula, $\lg [\mathrm{G}(\alpha)]$ has a linear relationship to $1 / \mathrm{T}$, thus, the thermogravimetric data of $\mathrm{Ka}-\mathrm{MeOH}-\mathrm{SS}$ can be used for linear fitting, and the values of $\mathrm{E}$ and $\mathrm{A}$ can be obtained through the slope and intercept. After the calculation, five mechanism functions with goodness of fit above $99 \%$ are chosen, and the values of $\mathrm{E}$ and $\mathrm{A}$ are in the normal range of de-intercalation kinetics $\left(\mathrm{E}=80-250 \mathrm{~kJ} \mathrm{~mol}^{-1}, \lg \left(\mathrm{A} / \mathrm{s}^{-1}\right)=7-30\right.$, see Table 1$)$.

Table 1. Results of experimental data by Satava integral method

\begin{tabular}{lccc}
\hline $\begin{array}{l}\text { Mechanism } \\
\text { unction }\end{array}$ & $\begin{array}{c}\text { Goodness of } \\
\text { fit } / \%\end{array}$ & $\mathrm{E} /\left(\mathrm{kJ} \mathrm{mol}^{-1}\right)$ & $\lg \left(\mathrm{A} / \mathrm{s}^{-1}\right)$ \\
\hline No. 9 function & 99.74 & 217.7 & 21.30 \\
No. 16 function & 99.27 & 98.3 & 9.71 \\
No. 17 function & 99.27 & 147.5 & 14.75 \\
No. 18 function & 99.27 & 196.7 & 19.84 \\
No. 36 function & 99.81 & 133.7 & 13.69 \\
\hline
\end{tabular}

Obviously, if only the optimal goodness of fit is used as criterion for the most probable mechanism function, No. 36 function is the optimal mechanism. However, the value of $\mathrm{E}$ is $91.8 \mathrm{~kJ} \mathrm{~mol}^{-1}$ based on Ozawa method, and the $\mathrm{E}$ of No. 16 function (i.e., $98.3 \mathrm{~kJ} \mathrm{~mol}^{-1}$ ) is closest to $91.8 \mathrm{~kJ} \mathrm{~mol}^{-1}$ with $\left|\mathrm{E}_{\mathrm{o}}-\mathrm{E}_{\mathrm{s}}\right| / \mathrm{E}_{\mathrm{o}}$ equals to 0.07 , that is lesser than 0.10 . Thus, No. 16 function (Figure $6 \mathrm{~b}$ ) is the most probable mechanism function of the de-intercalation reaction of $\mathrm{Ka}-\mathrm{MeOH}-\mathrm{SS}$. The mechanism function is $f(\alpha)=-\ln (1-\alpha), G(\alpha)=1-\alpha$.

\section{Structural model of Ka-MeOH-SS}

The analyses of XRD pattern and stereochemistry have been commonly used to infer the array pattern of organic molecules/ions between the layers of Ka. According to the FTIR and XRD results in this study, the intercalation mechanism of Ka-MeOH-SS is studied and an array pattern of sodium stearate between layers of $\mathrm{Ka}$ is put forward.

Figure 7 shows that the 001 reflection of $\mathrm{Ka}-\mathrm{MeOH}$ exists on the XRD pattern of Ka-MeOH-SS all the time. After $\mathrm{Ka}-\mathrm{MeOH}-\mathrm{SS}$ was washed by ethanol, the characteristic diffraction peak of $\mathrm{Ka}-\mathrm{MeOH}-\mathrm{SS}$ disappears, whereas the 001 reflection of $\mathrm{Ka}-\mathrm{MeOH}$ becomes more noticeable (Figure 7a). Furthermore, the intercalation ratio of $\mathrm{Ka}-\mathrm{MeOH}$
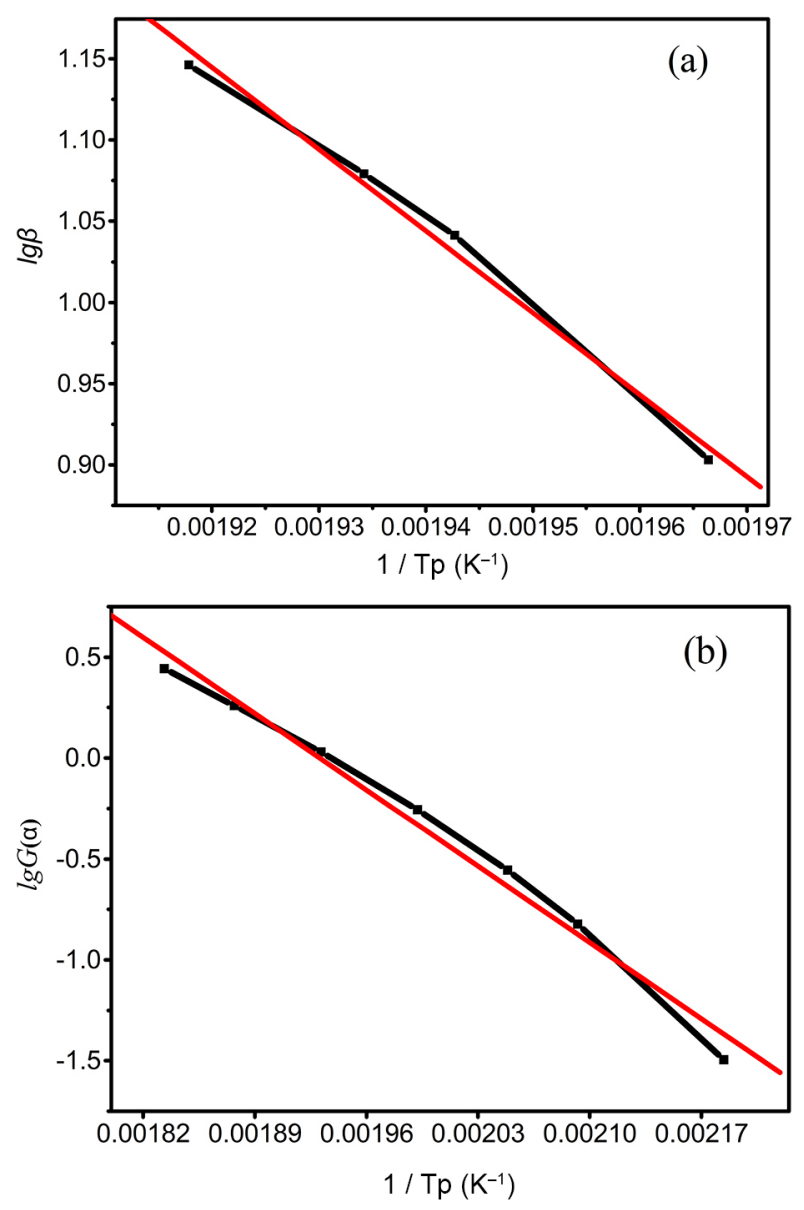

Figure 6. Linear fitting curves by Satava integral method (a) and Ozawa method (b).

intercalation compound is $89.5 \%$, approximately equal to that $(89.6 \%)$ where methanol molecules totally displaced DMSO (Figure 1c), implying that methanol remains being grafted on the surface of $\mathrm{AlO}_{2}(\mathrm{OH})_{4}$ octahedral sheets of Ka, that exist with sodium stearate in the interlayer space of $\mathrm{Ka}$ during the reaction process.

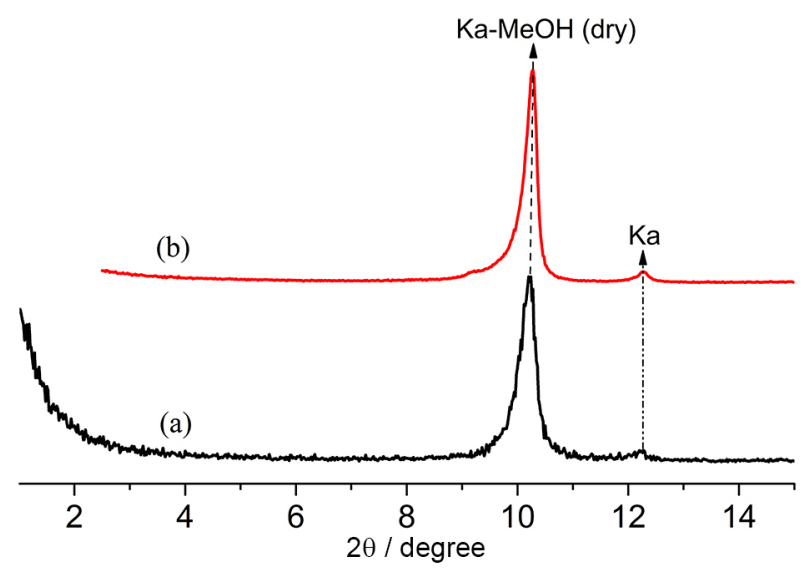

Figure 7. XRD patterns of $\mathrm{Ka}-\mathrm{MeOH}$ (dry) and $\mathrm{Ka}-\mathrm{MeOH}-\mathrm{SS}$ (after stearate radical ions deintercalating): (a) $\mathrm{Ka}-\mathrm{MeOH}-\mathrm{SS}$; (b) $\mathrm{Ka}-\mathrm{MeOH}$ (dry). 
$\mathrm{Ka}$ is prone to adsorb negative charges on its end face and surface. When sodium stearate was dissolved in water, stearate radical ions and hydrated sodium ions were formed. As a result, stearate radical ions approached the Ka gradually and finally formed hydrogen bonds with the two hydrogen atoms of $-\mathrm{CH}_{3}$ on the methoxyl groups, owing to their ability to attract protons of the two oxygen atoms on $-\mathrm{COO}^{-}$on stearate radical ions. Moreover, the $\mathrm{SiO}_{4}$ tetrahedral sheet of $\mathrm{Ka}$ is electronegative; hence, electropositive sodium ions were absorbed on its surface. According to the shift of the vibration bands of innersurface hydroxyls on the FTIR spectra, some sodium ions entered into the ditrigonal holes of the $\mathrm{SiO}_{4}$ tetrahedral sheets.

The length of the molecular chain of stearate radical ions along the macro-axis is $2.26 \mathrm{~nm}$. Methoxyl groups are grafted on the $\mathrm{AlO}_{2}(\mathrm{OH})_{4}$ octahedral sheets, and its molecular chain is as long as $0.16 \mathrm{~nm}$. Moreover, the $\mathrm{SiO}_{4}$ tetrahedral and $\mathrm{AlO}_{2}(\mathrm{OH})_{4}$ octahedral (TO) of Ka are as thick as $0.54 \mathrm{~nm}$. Obviously, within the $4.55-4.79 \mathrm{~nm}$ distance of interlayer space, $(4.55-4.79) \mathrm{nm}-0.16 \mathrm{~nm}-$ $0.54 \mathrm{~nm}=(3.85-4.09) \mathrm{nm}$ is left, excluding the thickness of methoxyl groups and TO. This length is larger than the length of stearate radical ions $(2.26 \mathrm{~nm})$, but smaller than the double length $(2.26 \mathrm{~nm} \times 2=4.52 \mathrm{~nm})$. Thus, two layers of stearate radical ions are arranged aslant during the interlay of Ka.

As for the two-layer gradient stearate radical ions, the $-\mathrm{CH}_{3}$ on one layer can form hydrogen bonds with $-\mathrm{C}=\mathrm{O}$ and $-\mathrm{C}-\mathrm{O}$ on the other layer, which result in that the layer on which $-\mathrm{COO}^{-}$has not combined with methoxyl groups arrange towards the interlayer space of Ka. From the perspective of electrostatic attraction, some hydrate sodium ions can be absorbed around this layer. According to the radius of sodium ion $(0.10 \mathrm{~nm})$ and the thickness of hydrate layer (about $0.16 \mathrm{~nm}$ ), the diameter of hydrate sodium ion is calculated to be $(0.16 \mathrm{~nm} \times 2)+(0.10 \mathrm{~nm} \times 2)=0.52 \mathrm{~nm}$. Based on previous data, the inclination angle of stearate radical ions in the interlayer space of kaolinite is $47.45^{\circ}$ to $52.17^{\circ}$. Figure 8 displays the interlamination structure of Ka-MeOH-SS.

\section{Conclusions}

$\mathrm{Ka}-\mathrm{MeOH}-\mathrm{SS}$ was prepared using $\mathrm{Ka}-\mathrm{MeOH}$ as the precursor; analysis through XRD and FTIR revealed that the interlamellar spacing of Ka-MeOH-SS was 45.5-47.9 and the intercalation ratio was $80.2 \%$. Reaction duration exerted the inclination angle of sodium stearate between the interlayer: the interlamellar spacing of $\mathrm{Ka}-\mathrm{MeOH}-\mathrm{SS}$ would enlarge with prolonged time.

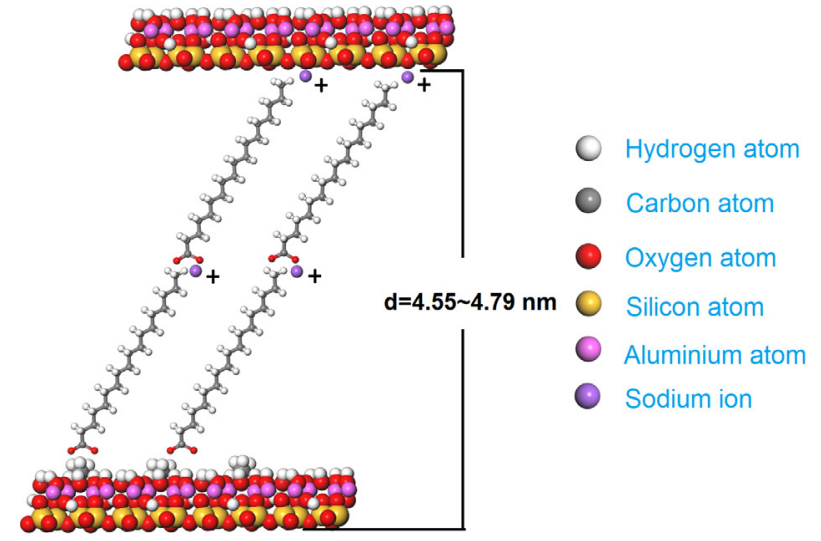

Figure 8. Possible structural model of Ka-methanol-sodium stearate intercalation compound.

Intercalation of sodium stearate destroyed the hydrogen bonds between adjacent layers, resulting in some frizzled layers of $\mathrm{Ka}-\mathrm{MeOH}-\mathrm{SS}$. Thermal analysis revealed three steps in the thermal de-intercalation of $\mathrm{Ka}-\mathrm{MeOH}-\mathrm{SS}$; its de-intercalation reaction conformed to the Mample Separate Law. The most probable mechanism was obtained as random nucleation and subsequent growth. Every particle was assumed to have one nucleus, A1, F1, and S shaped $\alpha$-t curve $(n=1, m=1)$. The functions of most probable mechanism, activation energy $\mathrm{E}$ and pre-exponential factor were found to be $f(\alpha)=-\ln (1-\alpha), G(\alpha)=1-\alpha$, $\mathrm{E}=98.3 \mathrm{~kJ} \mathrm{~mol}^{-1}$ and $\lg \left(\mathrm{A} / \mathrm{s}^{-1}\right)=9.71$, respectively.

The stearate radical ions were grafted on the methoxy groups and aslant arrayed in the interlayer space of $\mathrm{Ka}$ with an inclination angle of $47.45^{\circ}$ to $52.17^{\circ}$. Sodium ions were absorbed around the $\mathrm{SiO}_{4}$ tetrahedron and interlaminar $-\mathrm{COO}^{-}$, whereas some ions entered into the ditrigonal hole of the tetrahedral sheets. The preparation of $\mathrm{Ka}-\mathrm{MeOH}-\mathrm{SS}$ enlarged the scale of the Ka intercalator and provided a new method for exfoliation of Ka. This process is beneficial for increasing the value and expanding the application of Ka.

\section{Acknowledgments}

The authors are grateful to the financial support from the National Natural Science Foundation of China (No. 51034006), Beijing Joint-Construction Project (20121141301) and Beijing Nova Program (xx2015B081).

\section{References}

1. Ogawa, M.; Kuroda, K.; Chem. Rev. 1995, 95, 399.

2. Khan, A. I.; O'Hare, D.; J. Mater. Chem. 2002, 12, 3191.

3. Letaief, S.; Tonle, I. K.; Diaco, T.; Detellier, C.; Appl. Clay Sci. 2008, 42, 95 . 
4. Park, Y.; Ayoko, G. A.; Kristof, J.; Horváth, E.; Forst, R. L.; J. Therm. Anal. Calorim. 2012, 110, 1087.

5. Hu, H.; Gan, M.; Ma, L.; Li, Z.; Li, Y.; Ge, C.; Tu, Y.; Yu, L.; Huang, H.; Yang, F.; Compos. Sci. Technol. 2014, 104, 9.

6. Zhang, S.; Liu, Q.; Cheng, H.; Zhang, Y.; Li, X.; Forst, R. L.; Appl. Clay Sci. 2015, 114, 484.

7. Dedzo, G. K.; Detellier, C.; Appl. Clay Sci. 2014, 97-98, 153.

8. Frost, R. L.; Kristof, J.; Horvath, E.; Kloprogge, J. T.; Thermochim. Acta 1999, 327, 155.

9. Gardolinski, J. E.; Carrera, L. C. M.; Cantão, M. P.; Wypych, F.; J. Mater. Sci. 2000, 35, 3113.

10. Makó, E.; Kristóf, J.; Horváth, E.; Vágvölgyi, V.; J. Colloid Interface Sci. 2009, 330, 367.

11. Ledoux, R. L.; White, J. L.; J. Colloid Interface Sci. 1966, 21 , 127.

12. Frost, R. L.; Locos, O. B.; Kristof, J.; Kloprogge, J. T.; Vib. Spectrosc. 2001, 26, 33.

13. Frost, R. L.; Kristof, J.; Rintoul, L.; Kloprogge, J. T.; Spectrochim. Acta, Part A 2000, 56a, 1681.

14. Cruz, M. D. R.; Franco, F.; Clays Clay Miner. 2000, 48, 586.

15. Komori, Y.; Sugahara, Y.; Kuroda, K.; Appl. Clay Sci. 1999, 15, 241.

16. Matusik, J.; Kłapyta, Z.; Appl. Clay Sci. 2013, 83-84, 433.

17. Sidheswaran, P.; Bhat, A. N.; Ganguli, P.; Clays Clay Miner. 1990, 38, 29.

18. Yuan, P.; Tan, D.; Annabi-Bergaya, F.; Yan, W.; Liu, D.; Liu, Z.; Appl. Clay Sci. 2013, 83-84, 68.

19. Martens, W. N.; Frost, R. L.; Kristof, J.; Horvath, E.; J. Phys. Chem. 2002, 106, 4162.

20. Thompson, J. G.; Clays Clay Miner. 1985, 33, 490.

21. Raupach, M.; Barron, P. F.; Thompson, J. G.; Clays Clay Miner. 1987, 35, 208.
22. Tunney, J. J.; Detellier, C.; J. Mater. Chem. 1996, 6, 1679.

23. Lagaly, G.; Ogawa, M.; Dekany, M. In Handbook of Clay Science; Bergaya, F.; Theng, B. K. G.; Lagaly, G., eds.; Elsevier: Amsterdam, 2006, pp. 355.

24. Guerra, D. L.; Airoldi, C.; J. Braz. Chem. Soc. 2009, 20, 19.

25. Adams, J. M.; Clays Clay Miner. 1978, 26, 169.

26. Letaief, S.; Elbokl, T. A.; Detellier, C.; J. Colloid Interface Sci. 2006, 302, 254.

27. Elbokl, T. A.; Detellier, C.; J. Colloid Interface Sci. 2008, 323, 338.

28. Kuroda, Y.; Ito, K.; Itabashi, K.; Kuroda, K.; Langmuir 2011, 27, 2028.

29. Cheng, H.; Liu, Q.; Yang, J.; Ma, S.; Frost, R. L.; Thermochim. Acta 2012, 545, 1.

30. Ptáček, P.; Šoukal, F.; Opravil, T.; Nosková, M.; Havlica, J.; Brandštetr, J.; Powder Technol. 2010, 203, 272.

31. Yang, S. Q.; Yuan, P.; He, H. P.; Qin, Z. H.; Zhou, Q.; Zhu, J. X.; Liu, D.; Appl. Clay Sci. 2012, 62-63, 8.

32. Faria, E. H. D.; Ciuffi, K. J.; Nassar, E. J.; Vicente, M. A.; Trujillano, R.; Calefi, P. S.; Appl. Clay Sci. 2010, 48, 516.

33. Elbokl, T. A.; Detellier, C.; J. Colloid Interface Sci. 2008, 323 , 338.

34. Sahnoune, F.; Saheb, N.; Khamel, B.; Takkouk, Z.; J. Therm. Anal. Calorim. 2012, 107, 1067.

35. Cheng, H.; Liu, Q.; Cui, X.; Zhang, Q.; Zhang, Z.; Frost, R. L.; J. Colloid Interface Sci. 2012, 376, 47.

36. Smith, M. E.; Neal, G.; Trigg, M. B.; Drennan, J.; Appl. Magn. Reson. 1993, 4, 157.

37. Elder, J. P.; Thermochim. Acta 1998, 318, 229.

Submitted: November 10, 2015

Published online: May 5, 2016 